\title{
Hot tearing in polycrystalline Ni-based IN738LC superalloy: Influence of $\mathrm{Zr}$ content
}

\author{
D. Heydari ${ }^{\mathrm{a}, *}$, A. Shahkaram Fard ${ }^{\mathrm{a}}$, A. Bakhshi ${ }^{\mathrm{a}}$, J.M. Drezet ${ }^{\mathrm{b}}$ \\ a Mapna Turbine Blade Engineering E Manufacturing Co., P.O. Box 31755-114, Karaj, Iran \\ ${ }^{b}$ Ecole Polytechnique Federale de Lausanne, LSMX, CH-1015 Lausanne, Switzerland
}

\section{A R T I C L E I N F O}

Article history:

Received 10 June 2013

Received in revised form 1 October 2013

Accepted 3 October 2013

Available online 22 October 2013

\section{Keywords:}

Hot tearing

Ni-base superalloy

Investment casting

Turbine blade

\begin{abstract}
A B S T R A C T
Zirconium is always present in Ni base superalloys as it enhances their creep properties. In the present study, the influence of very small $\mathrm{Zr}$ additions, $100-400 \mathrm{ppm}$, i.e. $0.01-0.04 \mathrm{wt}$.\%, on hot tearing of IN738LC superalloy is experimentally investigated using dedicated turbine blade castings. Although the $\mathrm{Zr}$ content remains very small, it has a strong effect on hot tearing tendency. Microstructure of hot tear in as-cast samples reveal that grain size and secondary dendrite arm spacing have no significant effect on hot tearing. On the other hand eutectic phase volume fraction and its dispersion or spreading along grain boundaries drastically affect the hot tearing propensity and strongly increase with increasing amounts of Zr. Hence grain coalescence becomes impossible at grain boundaries covered with eutectic phase films. With increasing $\mathrm{Zr}$ content, gain coalescence between two distinct grains with no interdendritic phase requires more undercooling. Coalescence is retarded and occurs deeper in the mush zone, i.e. at lower temperatures resulting in a higher sensitivity to hot tearing. Finally, it is shown that a reduction of $\mathrm{Zr}$ content to $0.02 \mathrm{wt}$.\% is required to fully suppress hot tearing in polycrystalline IN738LC blades.
\end{abstract}

(c) 2013 Elsevier B.V. All rights reserved.

\section{Introduction}

Hot cracking also known as hot tearing or solidification cracking, is an intergranular cracking due to lack of liquid feeding during the final steps of solidification as a result of poor dendritic grain coalescence. Casting parameters such as melt pouring temperature, cooling rate, mold rigidity and chemical composition of the alloy have noticeable effects on this phenomenon. Many studies have been established to characterize hot tear tendency using independent criteria. For instance, Rappaz et al. (1999) have derived a physically based hot tearing criterion that takes into account both thermal straining of the solid plus liquid structure and solidification shrinkage that can hardly be compensated by liquid feeding deep in the mushy zone because of the low local permeability. An excellent review by Eskin and Suyitno Katgerman (2004) is presenting solidification cracking and associated hot tearing criteria in details.

The effect of chemical composition on hot tearing appeares to be more complicated than the influence of casting parameters. Zhang (2003) has shown that variations of Ti and Ta contents affect hot tear tendency in IN792 through a variation of both the solidification interval and the amount of eutectic $\gamma / \gamma^{\prime}$. Zhang and Singer $(2004 a, b)$ have investigated the effect of $\mathrm{Zr}$ and $\mathrm{B}$ contents on the

\footnotetext{
* Corresponding author. Tel.: +9125861198.

E-mail address: heidari.davoud@mapnablade.com (D. Heydari).
}

formation of the eutectic phase and their influence on hot tearing of IN792. They showed that the solidification interval cannot solely explain the hot tearing tendency. Moreover in another study Zhang and Singer (2004a,b) obtained a crack free specimen with grain boundary misorientation angle less than $12^{\circ}$. Zhou et al. (2005) investigated the grain boundary characteristics and proved that the presence of an interdendritic eutectic phase supresses hot tearing. Zhou and Volek (2006) explored the effect of grain boundary (GB) fraction and showed higher GB fraction has a positive effect on lowering the hot tear tendency. Zhou and Volek (2007) found that smaller dendrite arm spacing's have a similar effect owing to an improved grain boundary cohesion. In another investigation, Zhou and Volek (2008) have studied the influence of carbides formation before final eutectic phase formation on grain boundary coalescence during solidification of CMSX-4. Results showed that carbide bridging improve cast ability for the same reason.

Sistaninia et al. (2012) studied grain boundaries as they are the location for solidification cracking. Rappaz et al. (2003) showed that intragranular coalescence occurs at a low solid fraction whereas grain coalescence (intergranular) takes place much deeper in the mushy zone at a higher solid fraction around 99\%. They have derived the undercooling required for coalescence of two different grains assuming no interdendritic phase are present in the liquid film. This undercooling is a function of grain boundary energy $\left(\gamma_{g b}\right)$ depending on misorientation between two grains, solid/liquid interfacial 

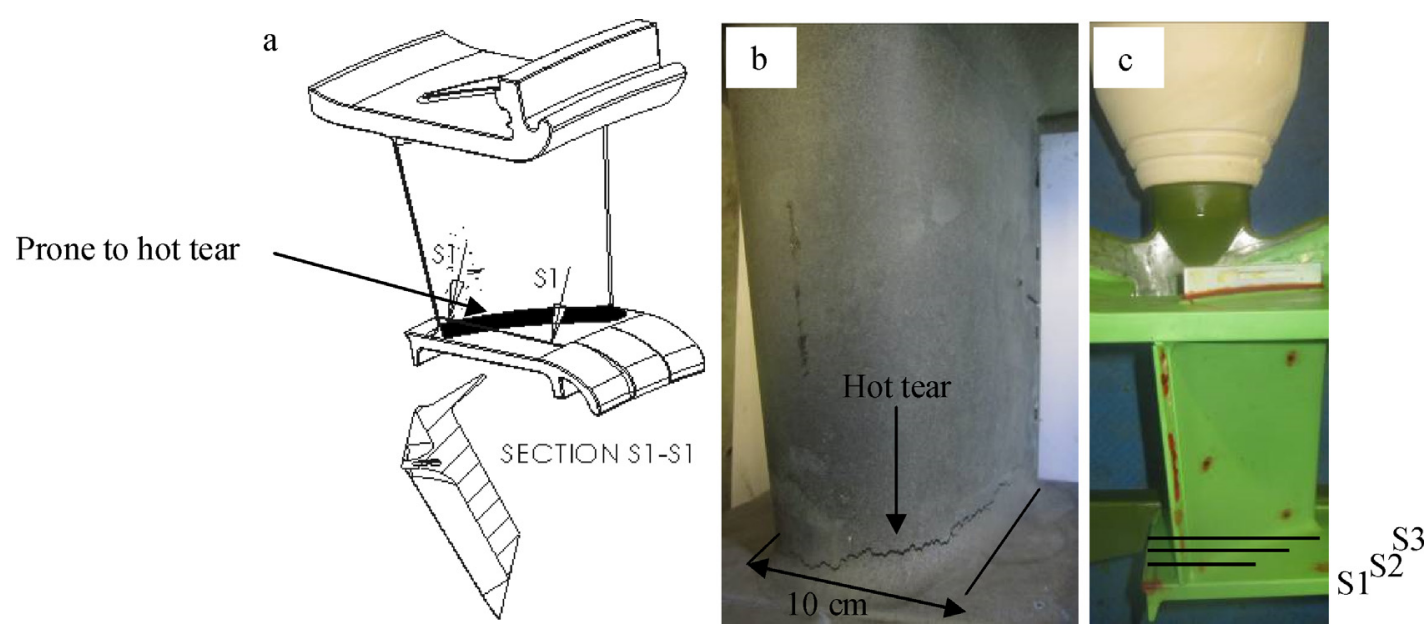

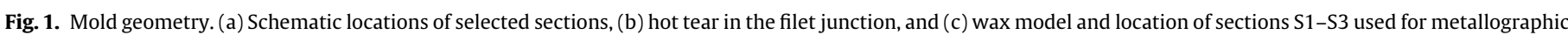
examinations.

Table 1

Nominal composition of the cast IN738LC superalloy.

\begin{tabular}{|c|c|c|c|c|c|c|c|c|c|c|c|c|}
\hline Elements & $\mathrm{Ni}$ & $\mathrm{Cr}$ & Co & $\mathrm{Ti}$ & $\mathrm{Al}$ & Ta & W & Mo & $\mathrm{Zr}$ & B & C & $\mathrm{Fe}$ \\
\hline wt.\% & Balanced & 16.1 & 9 & 3.4 & 3.3 & 1.8 & 2.8 & 1.85 & 0.01 to 0.04 & 0.008 & 0.1 & 0.021 \\
\hline
\end{tabular}

energy $\left(\gamma_{s l}\right)$, entropy of fusion $\left(\Delta S_{f}\right)$ and thickness of the liquid film $(\delta)$ :

$\Delta T_{b}=\frac{\gamma_{g b}-2 \gamma_{s l}}{\Delta S_{f}}\left(\frac{1}{\delta}\right)$

Wang et al. (2004) have confirmed this concept by welding two single crystal plates. By increasing crystallographic misorientation between the two crystals, the hot tearing tendency increased because of increasing grain boundary energy.

As reported by Farup et al. (2001), solid parts deform during solidification in a ductile manner but part of this deformation is transmitted to the adjacent mushy zone at regions where liquid films are still present, i.e. at grain boundaries. Trace element contents have a large influence on grain coalescence and thus on hot tearing. Although they are considered as trace elements, $\mathrm{Zr}$ and $B$ greatly influence the interfacial solid liquid energy and thus grain coalescence and hot tearing. One of the most remarkable alloying effects in superalloys is the enhancement of creep properties using minute additions of boron and zirconium that cannot be totally removed in polycrystalline $\mathrm{Ni}$-base superalloys. Content of these trace elements should be optimized according to mechanical acceptance criteria and cast ability.

In the present work, the influence of $\mathrm{Zr}$ content on hot tearing susceptibility of polycrystalline IN738LC is studied. The findings are discussed in terms of grain coalescence and presence or absence of phases at grain boundaries.

\section{Experimental}

The wax patterns as shown in Fig. 1c were injected and then subjected to a robot dipping and stuccoing program in order to minimize shell thickness variation in each cluster. After de-waxing, all ceramic molds were preheated to $1000^{\circ} \mathrm{C}$ for $2 \mathrm{~h}$. Ni-based IN738LC superalloy was cast at $1415^{\circ} \mathrm{C}$ in a vacuum induction furnace under a pressure of 0.003 mbar. The actual composition of the IN738LC superalloy is reported in Table 1. Four samples were cast with different $\mathrm{Zr}$ contents ranging from 0.01 to $0.04 \mathrm{wt}$.\%, using pure $\mathrm{Zr}$ master bars (99.99\%). Table 2 shows the $\mathrm{Zr}$ content variations in samples $1-4$.
Table 2

Variations in $\mathrm{Zr}$ content within the four different samples.

\begin{tabular}{ll}
\hline Sample & Zr content $(\mathrm{ppm})$ \\
\hline 1 & 100 \\
2 & 200 \\
3 & 300 \\
4 & 400 \\
\hline
\end{tabular}

Fig. 1a shows the section S1 of the cast samples where metallographic inspections were carried out. This particular section was selected because of the high risk of hot tearing at the filet junction.

Florescence penetrant inspection (FPI) test was carried out on the samples to reveal macro and micro cracks. Samples 1 and 4 were also cut in two other sections, S2 and S3, as shown in Fig. 1c for metallographic observations using BUEHLER expert system procedures described in Roskosz and Adamiec (2009). OM (optical microscopy) and SEM (scanning electron microscopy) microcopies were used to characterize the as-cast microstructures. Grain size and secondary dendrite arm spacing (SDAS) of the samples were determined using the linear intercept method.

\section{Results}

\subsection{Hot tearing severity}

Cast samples are shown in Fig. 2. No macro or micro crack was observed in samples 1 and 2 . However, samples 3 and 4 severely suffered from hot tearing which caused complete detachment of the filet area from the airfoil in sample 4 as illustrated in Fig. 2c. With $\mathrm{Zr}$ content increasing from $0.01 \mathrm{wt} . \%$ to $0.04 \mathrm{wt} . \%$, hot tearing appeared at $0.03 \mathrm{wt} . \% \mathrm{Zr}$ and worsened at $0.04 \mathrm{wt} . \%$, thus proving the high impact of minute amounts of $\mathrm{Zr}$ on the risk of hot tearing.

\subsection{Microstructure}

Eutectic phase fractions and morphologies along with the SDAS are reported for sections S1-S3 of samples 1 and 4 . Sample 1 is sound, i.e. free of solidification cracks, whereas the second one is fully damaged by many hot tears although both of them underwent 

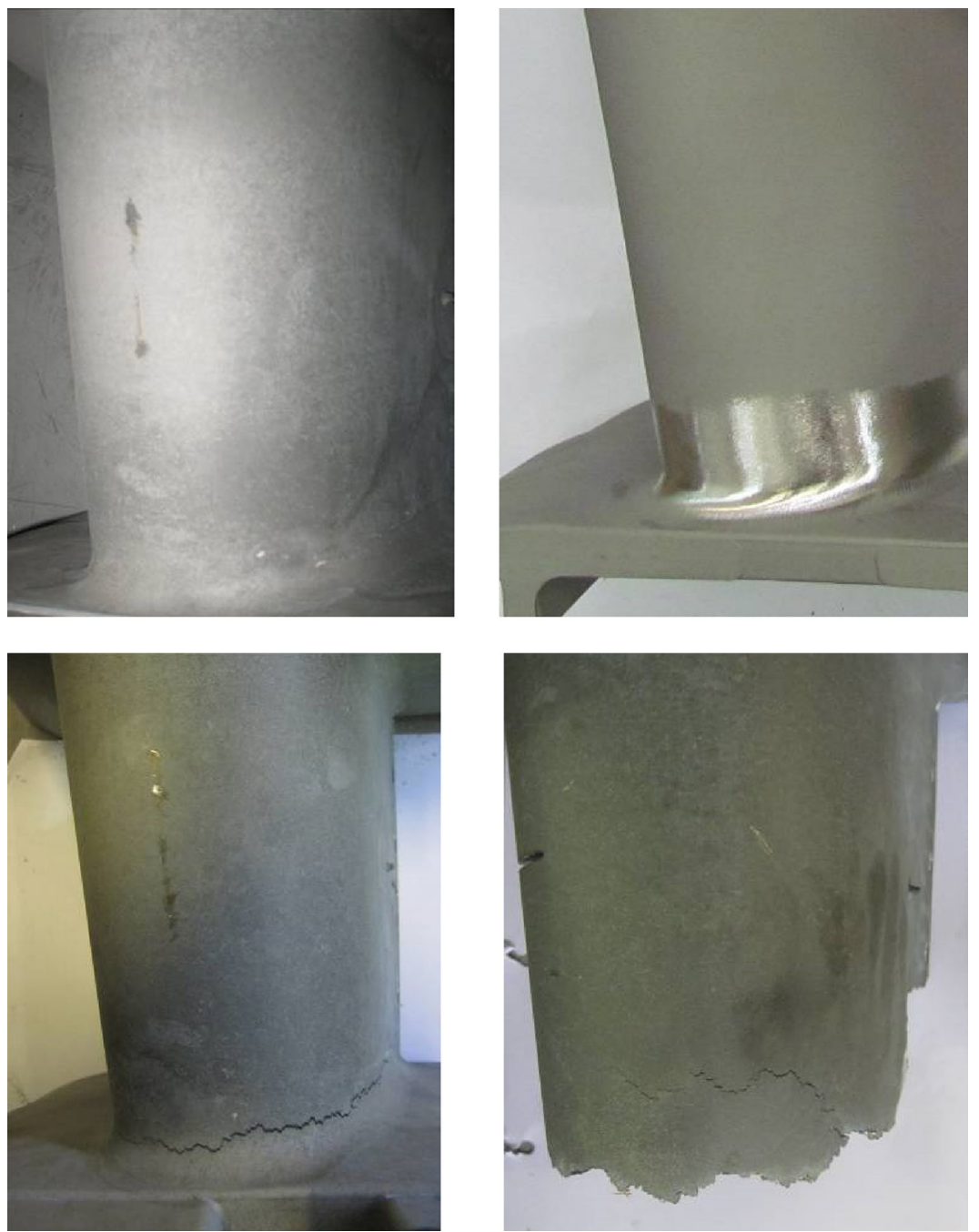

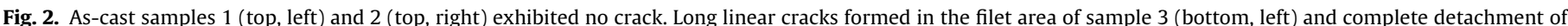
airfoil and filet occurred in sample 4 (bottom, right).

Table 3

Grain size close to hot tearing areas marked in Fig. 5.

\begin{tabular}{lccc}
\hline & $\mathrm{S} 1(\mathrm{~mm})$ & $\mathrm{S} 2(\mathrm{~mm})$ & $\mathrm{S} 3(\mathrm{~mm})$ \\
\hline Sample 1 & $3.5 \pm 0.3$ & $3.6 \pm 0.3$ & $3.6 \pm 0.3$ \\
Sample 4 & $3.5 \pm 0.2$ & $3.5 \pm 0.2$ & $3.6 \pm 0.2$ \\
\hline
\end{tabular}

Table 4

$\operatorname{SDAS}\left(\lambda_{2}\right)$ close to hot tearing areas marked in Fig. 5.

\begin{tabular}{llll}
\hline & $\mathrm{S} 1(\mu \mathrm{m})$ & $\mathrm{S} 2(\mu \mathrm{m})$ & $\mathrm{S} 3(\mu \mathrm{m})$ \\
\hline No. 1 & $210 \pm 26$ & $224 \pm 27$ & $258 \pm 28$ \\
No. 4 & $218 \pm 22$ & $238 \pm 31$ & $273 \pm 25$
\end{tabular}

the same casting conditions. Microstructure of sample 4 close to locations of hot tearing is illustrated in Fig. 3 at sections S1-S3.

Average grain size and SDAS of samples 1 and 4 are shown in Tables 3 and 4, respectively, for different sections. Results show that these parameters are approximately identical in each section and thus prove that neither grain size nor SDAS have a great influence on hot tearing.

Eutectic phase volume fractions of samples 1 and 4 are reported in Fig. 4. Results indicate that increasing $\mathrm{Zr}$ content greatly increases the eutectic phase volume fraction. In sample 4, the slight increase in the eutectic phase volume fraction is explained by a decreasing cooling rate when going from section S1-S3.

Microstructures of sample 1 and 4 are shown in Fig. 5. Both volume fraction of the eutectic $\gamma / \gamma^{\prime}$ phase and its spreading increase with increasing $\mathrm{Zr}$ content.

Fig. 6 shows micrographs at three different locations labeled 1-3 in section S3 very close to the hot tear surface of sample 4 . When going from location 1-3, i.e. with increasing distance to the hot tear, the eutectic $\gamma / \gamma^{\prime}$ phase becomes larger and elongated as a result of both higher cooling rate and $\mathrm{Zr}$ segregation. In addition, shrinkage porosity appears in the coarse eutectic $\gamma / \gamma^{\prime}$ at location 2. At location 3 , the intergranular propagation of the hot tear clearly appears.

Fig. 7 shows a zoom of the microstructure of sample 4 at location 3 (cf. Fig. 6) very close to the hot tear surface. Two grains appear in which intragranular eutectic has formed. The solidification crack has initiated in a micro-pore and propagated in the intergranular eutectic and has stopped when this eutectic disappeared, i.e. when the grain boundary becomes phase free. This is explained by the fact that coalescence occurs earlier in phase free grain boundaries.

El-Bagoury et al. (2008) reported that as-cast microstructure of IN738LC alloy consists of austenitic $\gamma$ matrix, carbides such as TiC or NbC and $\gamma / \gamma^{\prime}$ eutectic. SEM micrographs of carbide distribution at points 1 and 3 in section S3 of sample 4 (cf. Fig. 6) are presented in Fig. 8. Carbide volume fraction decreases from point $1-3$, i.e. 


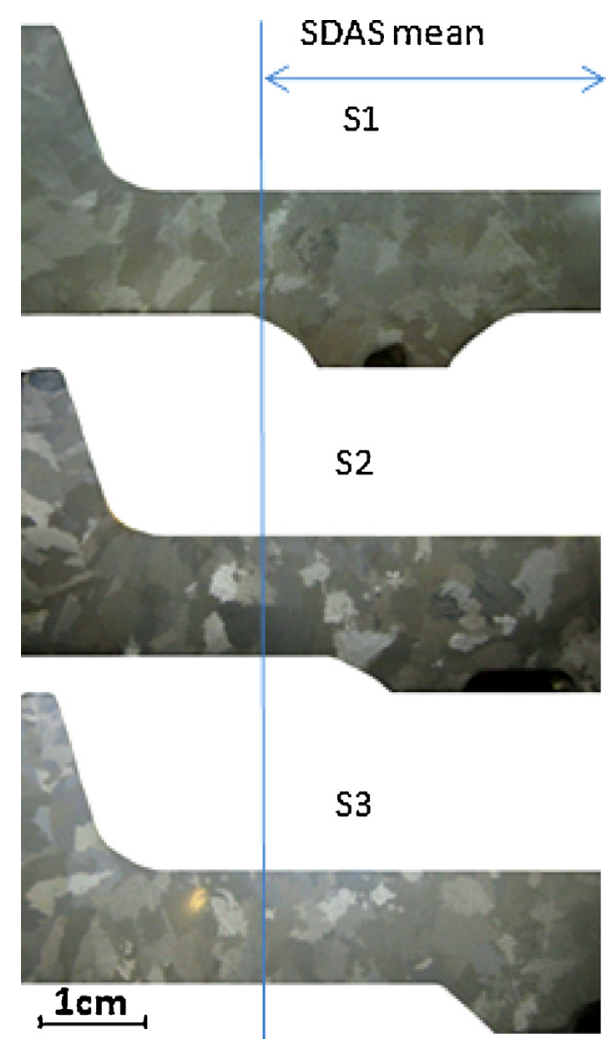

Fig. 3. Macrographs of S1-S3 sections close to hot tear locations in sample 4. The SDAS is the value averaged over the segment.

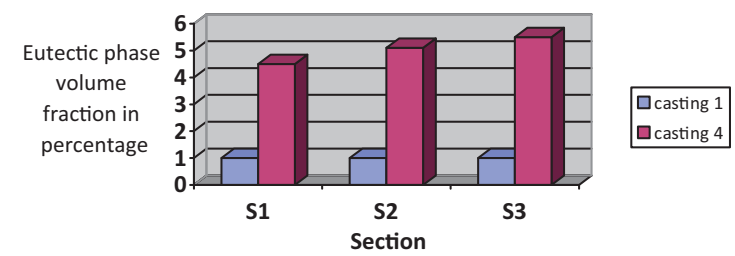

Fig. 4. Eutectic volume fraction in percentage in sections $\mathrm{S} 1-\mathrm{S} 3$ for samples 1 and 4 .

with decreasing cooling rate. Carbides become less continuous at location 3, i.e. their spreading is reduced.

\section{Discussion}

Campbell (1991) reported that microstructures with fine grain sizes better sustain straining of the mushy zone as deformation becomes more uniformly distributed over the grain boundaries. Consequently, these microstructures exhibit higher hot tearing resistance. Microstructure examination showed that there was no major difference between grain size in IN738LC samples 1 and 4, but sample 1 was sound and sample 4 was fully damaged. Similarly, SDAS was similar between samples 1 and 4 . These evidences reveal the influence of $\mathrm{Zr}$ on hot tearing is not linked with a change in microstructure.

Zhang and Singer (2004a,b) showed that even with $\mathrm{Zr}$ content as low as 0.04 wt.\%, i.e. 400 ppm, hot tearing cannot be explained by a larger solidification interval for IN792. Instead they attributed such a tendency to the presence and nature of intergranular phases. $\mathrm{Zr}$ has a great tendency to segregate in interdendritic regions and grain boundaries. As such it plays important role on the hot tearing susceptibility of the IN738LC superalloy. Ojo et al. (2004) reported that at high cooling rates, partition coefficient of $\mathrm{Zr}$ is around 0.13 in IN738LC. This segregation not only increases the volume fraction of eutectic but also its spreading along grain boundaries, as shown in Fig. 7. Spreading of eutectic phase at grain boundaries efficiently hinders grain coalescence and thus increases the risk of hot tearing. Motejadded et al. (2011) showed that Zr diffuses along grain boundaries around 4'200 faster than in intragranular zones. Also it has more solubility in $\gamma^{\prime}$ than in $\gamma$ phase. The $\mathrm{Zr}$ affinity to grain boundaries results in the formation of intergranular coarse eutectic phase pools, as can be seen in Fig. 6. The appearance of micro porosity in the eutectic phase at location 2 (cf. Fig. 6) is attributed to a local lack of liquid feeding during solidification in spite of the higher eutectic $\gamma / \gamma^{\prime}$ phase volume fraction. Indeed, higher amount of eutectic phase is known to reduce hot tearing propensity as local permeability is increased owing to the presence of larger intergranular channels. But this is true when the eutectic phases are spread all along the grain boundaries. In sample 4, the higher content of eutectic phase is due to the higher $\mathrm{Zr}$ content, $0.04 \mathrm{wt} . \%$. However, stresses concentrated at grain boundaries result in hot crack initiation and propagation as shown in Fig. 7. Dantzig and Rappaz (2009) have reported that mushy zones exhibit a brittle behavior near the end of solidification step at solid volume fractions around 0.95 when liquid permeability is too low and final liquid content is trapped in discontinuous thin films at grain boundaries. Increasing $\mathrm{Zr}$ content creates such a situation.

Gain boundary coalescence during solidification plays a critical role on hot tearing. Fig. 9 shows a fractography of the hot tear in sample 4 where a complete detachment of the filet from the airfoil occurred. This means that grain boundaries were completely wet when hot tear occurred. Higher eutectic phase volume fraction and its spreading at grain boundaries enhance hot tearing. However, according to Fig. 7, grain boundary coalescence is still possible in some places at grain boundaries but cannot happen in highly strained areas. $\mathrm{Zr}$ is a surface active element that decreases the solid-liquid interfacial energy $\gamma_{s l}$ and leads to an increase in the
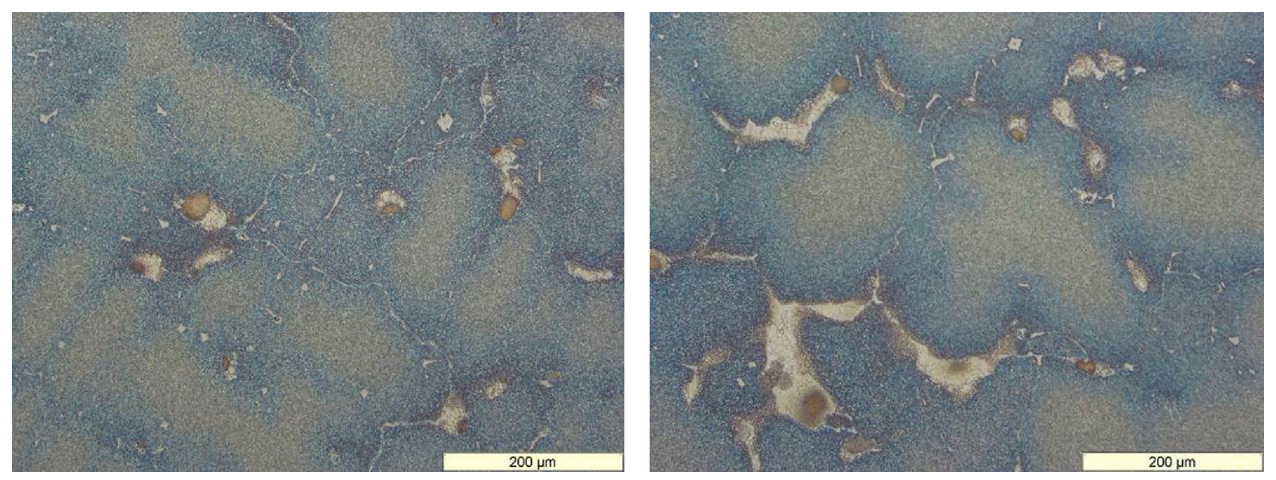

Fig. 5. Microstructure in sample 1 (left) and 4 (right). 


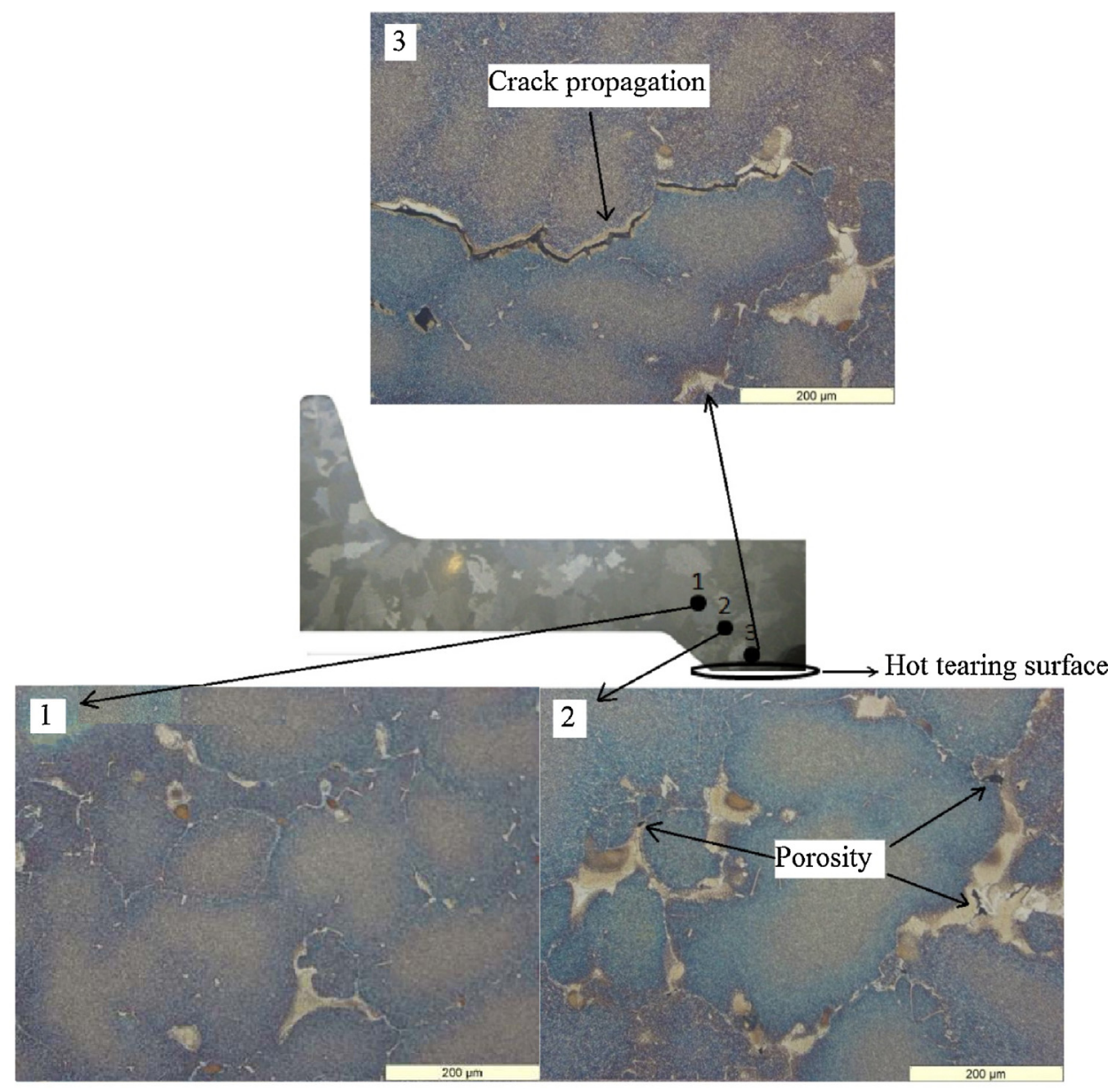

Fig. 6. Optical micrographs at the three locations labeled 1-3 in section S3 of sample 4.

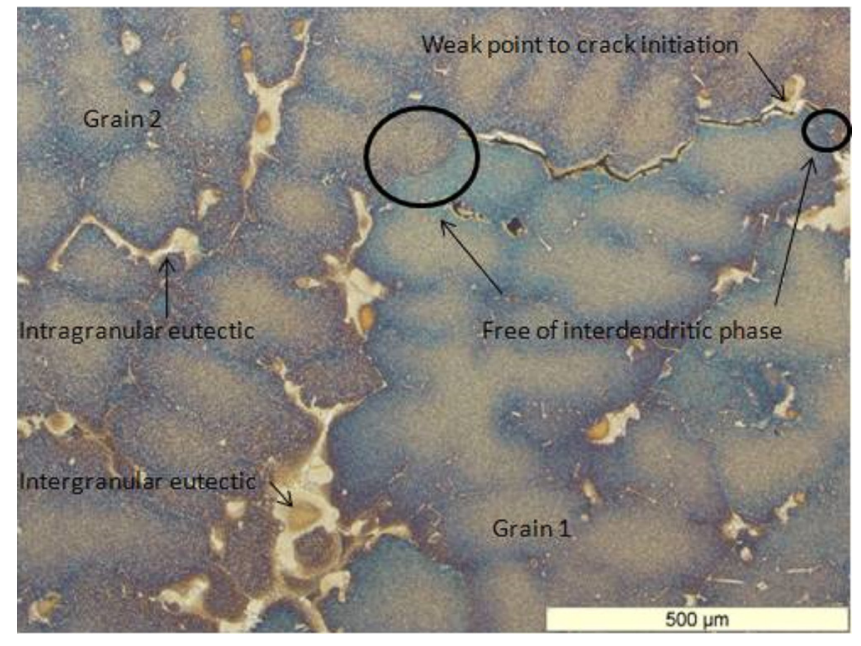

Fig. 7. Crack initiation and propagation in a grain boundary.

undercooling (cf. Eq. (1)) required for coalescence at eutectic and carbide free grain boundaries.

According to the microstructural investigations presented in Section 3, Zr addition influences hot tearing susceptibility in different ways.
(1) The eutectic phase present at grain boundaries cannot sustain tensile forces and thus increases hot tearing sensitivity. Increasing eutectic spreading at grain boundaries reduces the chance for grain bridging to occur and consequently increases hot tearing tendency. In the IN738LC superalloy, grain coalescence and thus bridging at phase free boundaries happens earlier, i.e. at temperatures higher than the temperature of eutectic formation. Therefore eutectic formation increases hot tearing sensitivity in two ways. First eutectic phase forms at lower temperatures, i.e. deeper in the mushy zone where stresses are higher (close to solid ductile alloy). Second, eutectic phase, such as isolated carbides, represents obstacles for intergranular liquid flow to feed the deep regions of mushy zone as schematically shown in Fig. 10.

With increasing $\mathrm{Zr}$ content, eutectic phase volume fraction and spreading at grain boundaries increase, thus reducing the liquid permeability in the mushy zone. Micro-pores can form in isolated liquid pools and play the role of initiation sited for hot tears.

(2) Carbides play a similar role when their spreading at grain boundaries is reduced and they tend to become isolated (cf. Fig. 8). As their volume fraction is low, their role on intergranular coalescence and hot tearing is negligible.

(3) In eutectic and carbide free grain boundaries, $\mathrm{Zr}$ addition increases the undercooling required for coalescence (cf. eq. 1). In other words, thin liquid films present at grain boundaries are more stable such as in sample 4 . Grain coalescence is retarded and occurs at lower temperatures. The undercooling defined 

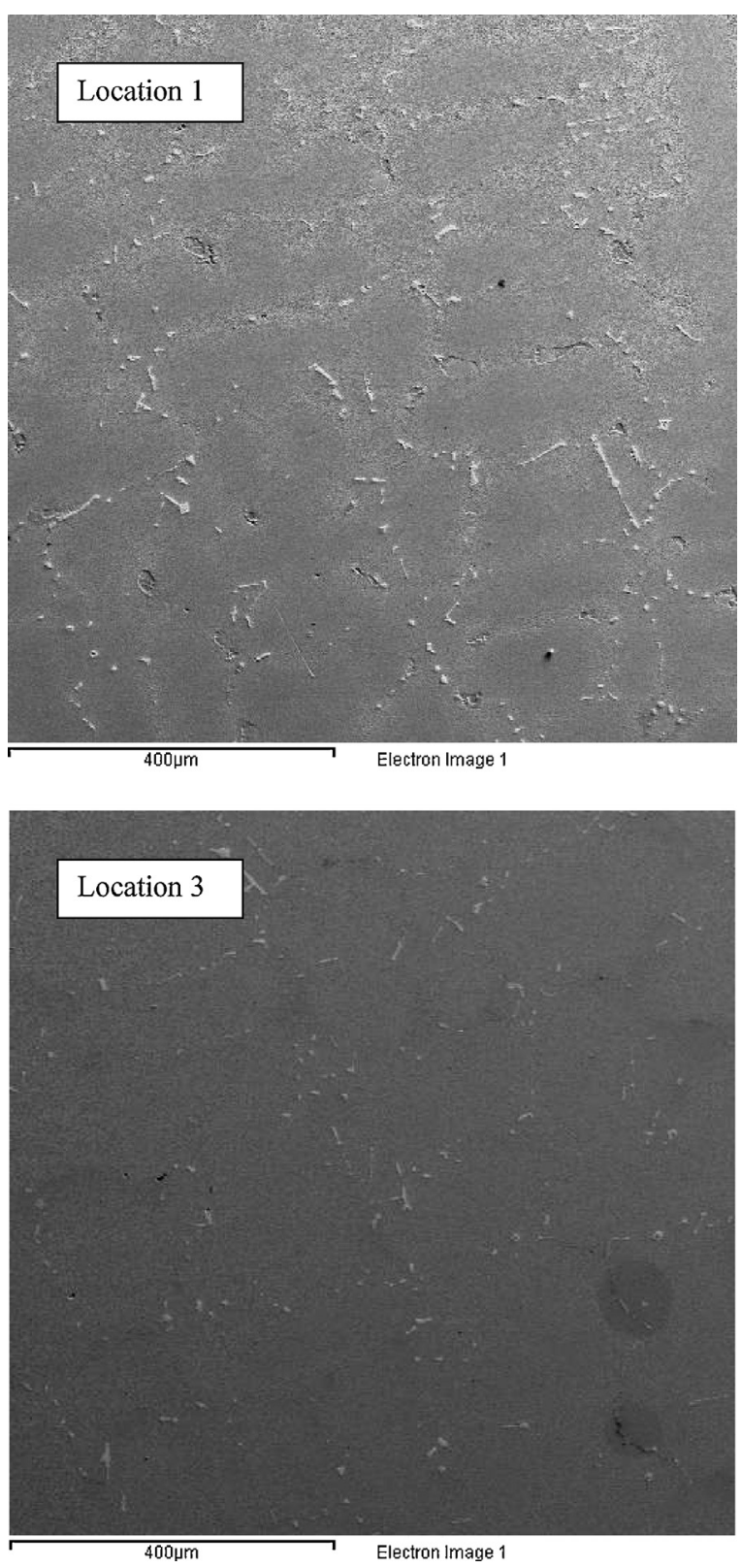

Fig. 8. carbides morphology spreading at locations 1 and 3 (cf. Fig. 6).

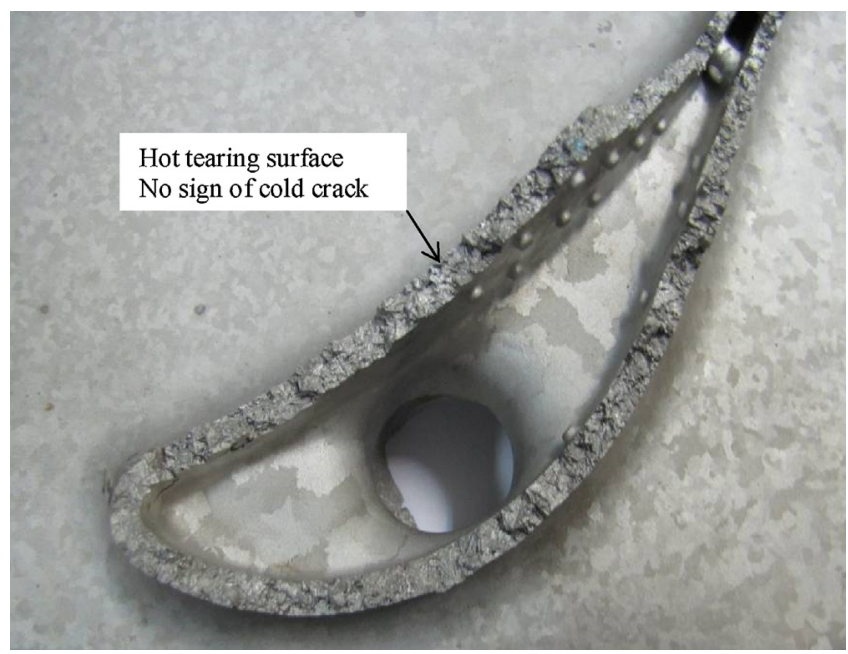

Fig. 9. complete fracture in sample 4 revealing a poor intergranular coalescence.

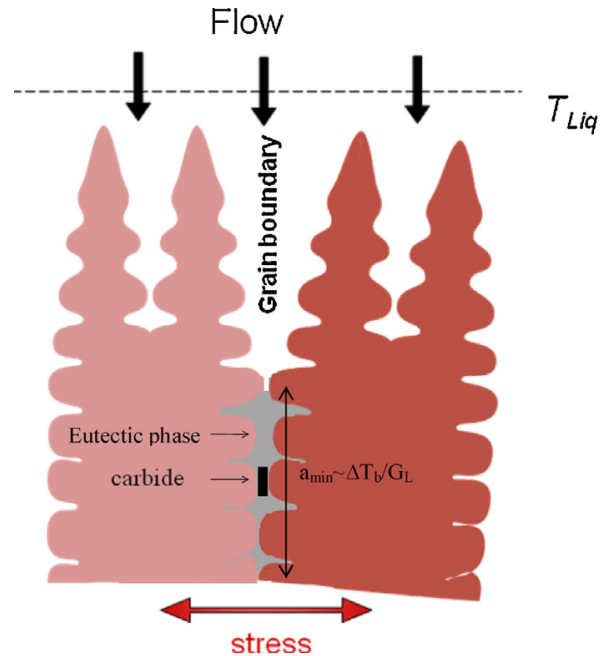

Fig. 10. Schematics of hot tear formation in alloys with $400 \mathrm{ppm} \mathrm{Zr}$. Adapted from Rappaz et al. (1999).

in eq. 1 allows us to determine the distance, $\Delta T_{b} / G_{L}$, where coalescence occurs. $\mathrm{G}_{\mathrm{L}}$ is the thermal gradient in the intergranular liquid Cf. Fig. 10). Increasing $\mathrm{Zr}$ content decreases grain coalescence temperature and thus increases hot tearing susceptibility.

By retarding grain coalescence and increasing eutectic phase content and spreading at grain boundaries, $\mathrm{Zr}$ additions highly reduce liquid permeability, stabilize liquid films during the last steps of solidification and thus enhance the risk of hot tearing. Castability of IN738LC superalloys is improved by a precise control of its chemical composition. In particular, $\mathrm{Zr}$ contents should remain lower than $200 \mathrm{ppm}$ to avoid the risk of hot tearing.

\section{Conclusion}

Small amounts of $\mathrm{Zr}$ have a tremendous influence on hot tearing tendency in IN738LC superalloys. With $\mathrm{Zr}$ levels increasing from $100 \mathrm{ppm}$ to $400 \mathrm{ppm}$, samples become more and more prone to hot tearing. This is explained by the following mechanisms:

(1) Zr segregates at grain boundaries in Ni-based superalloys. By increasing $\mathrm{Zr}$ content, eutectic phase volume fraction and its spreading along grain boundaries increase significantly. This hinders grain coalescence at grain boundaries covered with interdendritic phases. Both eutectic phase and isolated carbides represent obstacles for intergranular liquid flow to feed the deep regions of mushy zone.

(2) Dendrite coalescence at phase free grain boundaries is retarded by the presence of $\mathrm{Zr}$. This surface active element increases the solid liquid interfacial energy and thus increases the coalescence undercooling. Grain coalescence happens much deeper in the mushy zone where thermal strains are higher.

(3) Hence secondary dendrite arm spacing and grain size are less important factors for controlling hot tearing tendency in IN738LC superalloys in comparison with $\mathrm{Zr}$ content.

\section{Acknowledgements}

The authors would like to thank the Engineering and R\&D centre of PARTO and MAPNA group for the provision of alloys, furnaces, laboratory equipments and for financial support. 


\section{References}

Campbell, J., 1991. Castings. Butterworth-Heinemann, Oxford, United Kingdom, pp. 242-258.

Dantzig, J.A., Rappaz, M., 2009. Solidification. EPFL Press, pp. 556.

El-Bagoury, N., Waly, M., Nofal, A., 2008. Effect of various heat treatment conditions on microstructure of cast polycrystalline IN738LC alloy. Materials Science and Engineering A 487, 152-161.

Eskin, D.G., Suyitno Katgerman, L., 2004. Mechanical properties in the semi-solid state and hot tearing of aluminium alloys. Progress in Materials Science 49, 629-711.

Farup, I., Drezet, J.-M., Rappaz, M., 2001. In situ observation of hot tearing formation in succinonitrile-acetone. Acta Materialia 49, 1261-1269.

Motejadded, H.B., Soltanieh, M., Rastegari, S., 2011. Dissolution mechanism of a Zr rich structure in a $\mathrm{Ni}_{3} \mathrm{Al}$ base alloy. Journal of Materials Science and Technology 27, 885-892.

Ojo, O.A., Richards, N.L., Chaturvedi, M.C., 2004. Microstructural study of weld fusion zone of TIG welded IN 738LC nickel-based superalloy. Scripta Materialia 51, 683-688.

Rappaz, M., Drezet, J.-M., Gremaud, M., 1999. A new hot-tearing criterion. Metallurgical and Materials Transactions A 30 (February), 449-455.

Rappaz, M., Jacot, A., Boettinger, W.J., 2003. Last-stage solidification of alloys: theoretical model of dendrite-arm and grain coalescence. Metallurgical and Materials Transactions A 34 (march), 467-479.

Roskosz, S., Adamiec, J., 2009. Methodology of quantitative evaluation of porosity, dendrite arm spacing and grain size in directionally solidified blades made of CMSX-6 nickel alloy. Materials Characterization 60, 1120-1126.

Sistaninia., M., Phillion, A.B., Drezet, J.-M., Rappaz, M., 2012. Three-dimensional granular model of semi-solid metallic alloys undergoing solidification: fluid flow and localization of feeding. Acta Materialia 60, 3902-3911.

Wang, N., Mokadem, S., Rappaz, M., Kurz, W., 2004. Solidification cracking of superalloy single- and bi-crystals. Acta Materialia 52, 3173-3182.

Zhang, J., 2003. Effect of Ti and Ta on hot cracking susceptibility of directionally solidified Ni-based superalloy IN792. Scripta Materialia 48, 677-681.

Zhang, J., Singer, R.F., 2004a. Effect of $\mathrm{Zr}$ and B on castability of Ni-based superalloy IN792. Metallurgical and Materials Transactions A 35 (April), $1337-1342$.

Zhang, J., Singer, R.F., 2004b. Effect of grain boundary characteristics on castability of nickel-base superalloys. Metallurgical and Materials Transactions A 35 (March), 939-946.

Zhou, Y.Z., Volek, A., 2006. Effect of grain boundary fraction on castability of a directionally solidified nickel alloy. Scripta Materialia 54, 2169-2174.

Zhou, Y.Z., Volek, A., 2007. Effect of dendrite arm spacing on castability of a directionally solidified nickel alloy. Scripta Materialia 56, 537-540.

Zhou, Y.Z., Volek, A., 2008. Effect of carbon additions on hot tearing of a second generation nickel-base superalloy. Materials Science and Engineering A 479, 324-332.

Zhou, Y., Volek, A., Singer, R.F., 2005. Influence of solidification conditions on the castability of nickel-base superalloy IN792. Metallurgical and Materials Transactions A 36 (March), 651-6566. 